\title{
Microstructural Characterization of Zinc Alloy ZA27 with Modification and Heat Treatments
}

\author{
Shuo ZHANG, Xiaolin WEI, Wenbin YU ${ }^{a \star}$, Zheng LIAN, Huaizhi ZHAO \\ Faculty of Materials and Energy, Southwest University, Chongqing 400715, China \\ aemail: ywb2747@163.com
}

Keywords: Zinc Alloy; Modification; Heat Treatment; Microstructure

\begin{abstract}
The influence of $\mathrm{Ti}$ and $\mathrm{Zr}$ incorporated modification and heat treatments on microstructure of ZA27 zinc alloy were investigated in this work. The results of XRD and optical microscopy analyses showed that modification with the addition of $0.03 \mathrm{wt} . \% \mathrm{Ti}$ and $0.05 \mathrm{wt} . \% \mathrm{Zr}$ changed the morphology of primary $\alpha$-Al dendrite in ZA27 alloy from large branch-shape to small flower-shape without variation of phase constitution. It has been proposed that the segregation of $\mathrm{Ti}$ and $\mathrm{Zr}$ elements in the front of solidification interface influenced solute distributions and constitutional supercooling, and resulted in the change in growth pattern of block $\alpha$-Al dendrite and in the formation of secondary dendrite. It was found that modification improved the distribution of $\eta$-Zn phase in $\alpha$-Al matrix after solution heat treatment at $370^{\circ} \mathrm{C}$ for $10 \mathrm{~h}$, and obviously restrained the coarsening of eutectics during anneal heat treatments at $320^{\circ} \mathrm{C}$ for $3 \mathrm{~h}$ and $18 \mathrm{~h}$, respectively.
\end{abstract}

\section{Introduction}

High aluminum zinc based alloys have got rapid development as a new type of nonferrous alloy. ZA27 alloy is a kind of high strength cast alloy with a number of good mechanical performances, such as low density than copper and ferrous alloys, and high maximum tensile strength, good abrasive resistance, good load bearing, moderate heat conductivity and electric conductivity, etc. Now, ZA27 alloy has become an excellent substitute of wear-resistant materials, such as copper based alloys and cast irons, to manufacture wear-resistant parts, such as shaft sleeves, turbines, sliding blocks, etc. Moreover, ZA27 alloy is still of great application prospect in mould making industry [1]. Nonetheless, high aluminum zinc based alloys including ZA27 alloy are not desirable to be used in the fabrication of many important parts due to their inferior plasticity and toughness. Generally, ZA27 alloy needs to be improved in strength and toughness by means of modification and heat treatment, as well as other technological methods. Regarding to modification, many modifiers, such as boron, lithium, titanium, zirconium and rare earth elements, have been proved to enhance the plasticity and toughness of ZA27 alloy substantially through effectively grain refinement [2-4]. However, to date the modifying approach and effect of modifiers for ZA27 alloy is still lack of deep understanding, and the modifying mechanism has not got consistent opinion [5-7]. There is still lack of theoretical direction for modification of ZA27 alloy and lack of the understanding of heat treatment method [8].

According to the binary phase diagram of Al-Zn alloys [9], as shown in Fig.1, the solidification process and microstructure evolution of ZA27 alloy is fairly complex due to the existence of uniform grain, eutectic and segregation and other reactions on the non-balanced solidification condition. It is expectable that these reactions will be influenced to some extent by adding modification agents. For this reason the present work investigated the effect of $\mathrm{Ti}$ and $\mathrm{Zr}$ elements as incorporated modifiers, and the effect of some kind of subsequent heat treatments on the microstructure evolution of ZA27 alloy. 


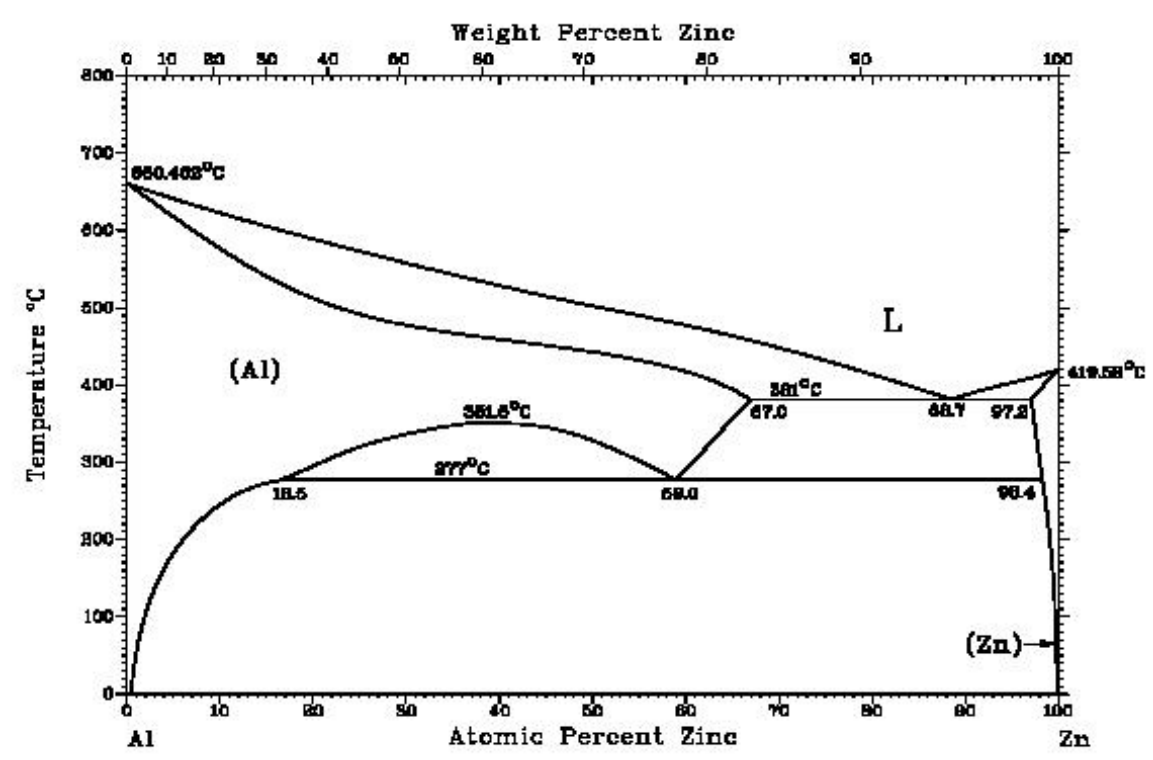

Fig.1. Equilibrium binary phase diagram of Al-Zn alloys

\section{Experimental procedures}

Materials and preparation: The raw materials used in this study were commercial pure aluminum, pure zinc, pure magnesium and $\mathrm{Al}-10 \% \mathrm{Cu}$ (mass fraction) master alloy. The modifiers $\mathrm{Ti}$ and $\mathrm{Zr}$ elements were induced by the $\mathrm{Al}-3 \% \mathrm{Ti}$ and $\mathrm{Mg}-33 \% \mathrm{Zr}$ master alloys. Pure $\mathrm{Zn}, \mathrm{Al}$ ingots and $\mathrm{Al}-10 \% \mathrm{Cu}$ master alloy were first melted at $720^{\circ} \mathrm{C}$ by use of electrical resistant furnace in a stainless steel crucible. After refined by $\mathrm{ZnCl} 2$ with manually stirring, pure $\mathrm{Mg}$ was added into the melt subsequently and pre-modified samples were cast after standing for 5-10min. Then the $\mathrm{Al}-3 \% \mathrm{Ti}$ and Mg-33\%Zr master alloys were added into the melt with stirring. Finally the melt was poured to metal mould to get modified samples. The chemical compositions of the cast ZA27 alloy with and without modification were listed in table 1.

Table.1. Chemical composition of ZA27 alloys investigated (\%, mass fraction).

\begin{tabular}{lcccccc}
\hline element & $\mathrm{Al}$ & $\mathrm{Cu}$ & $\mathrm{Mg}$ & $\mathrm{Ti}$ & $\mathrm{Zr}$ & $\mathrm{Zn}$ \\
\hline without modification & 25.4 & 2.4 & 0.10 & & & balance \\
with modification & 26.1 & 2.3 & 0.12 & 0.03 & 0.05 & balance \\
\hline
\end{tabular}

Heat treatments: The solution heat treatment and anneal heat treatment were conducted on the as-cast samples of the experimental ZA27 alloys. Both alloys with and without modifications were heat treated in the same regime. The solution samples were heated to $370^{\circ} \mathrm{C}$ and held for 10 hours in an electric furnace and quenched in water immediately. The annealing samples were heat treated at $320^{\circ} \mathrm{C}$ and held for 3 and 18 hours, respectively, and cooled in air.

Microstructural characterization: All samples were etched using 4\% Nital after pre-grinding and polishing, and observed under an optical microscopy, Zeise 200 MAT type. Grain size and volume fraction of phase was measured by use of the image analysis software (MZLY). The phase components of the investigated alloys were determined by means of X-ray diffraction (XRD), DX-2000 type. Differential thermal analysis (DSC) was conducted for both alloys with and without modification, by using the apparatus of NETZSCH STA-409PC type.

\section{Results}

As-cast microstructures: The XRD spectrums of investigated ZA27 alloys with and without modification are shown in Fig.2. It indicates that both alloys are composed of $\alpha$-Al, $\eta$ - Zn and $\varepsilon-\mathrm{CuZn}_{5}$ phases, which means that no phase composition change occurs in ZA27 alloy after Ti and $\mathrm{Zr}$ incorporated modification. Fig. 3 shows the DSC curves of the alloys, it reveals that the alloys 
undergo eutectic reaction and monotectoid reaction during solidification and cooling processes, respectively. It is obvious that the modification increases the monotectoid temperature and decreases the eutectic temperature and melting point of ZA27 alloy.

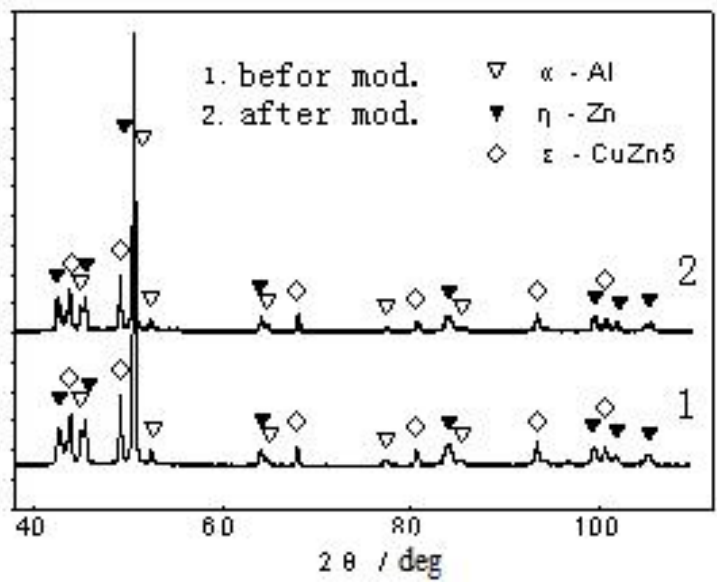

Fig.2. XRD patterns of as-cast ZA27 alloys

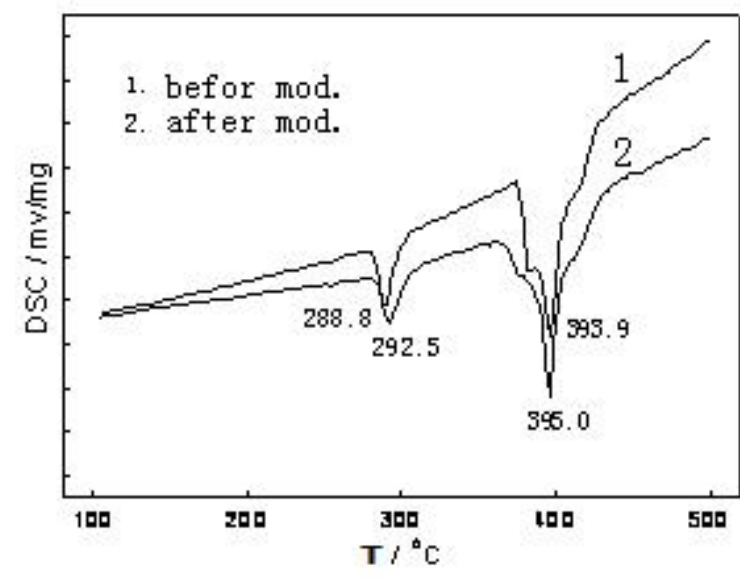

Fig.3. DSC curves of ZA27 alloys

Microstructures of as-cast ZA27 alloy with and without modification are shown in Fig.4. Without modification, the microstructure of ZA27 alloy is composed of developed integral dendrites of primary $\alpha$-Al solid solution and eutectics between them. The volume fraction of primary $\alpha$-Al dendrite is large above $65 \%$ and its mean length is about $200 \mu \mathrm{m}$ with no growth directionality, as shown in Fig.4(a). From the high magnitude image, Fig.4(b), it can be seen that the secondary dendrite arms are very developed with the secondary dendrite arms spacing (SDAS) of about $10 \mu \mathrm{m}$. The black spots between SDAS are $\eta-Z n$ phase and the areas between primary dendrite are lamellar $\alpha+\eta$ eutectics mingling with fine $\varepsilon-\mathrm{CuZn}_{5}$ compound. With modification, the microstructure of ZA27 alloy is still composed of integral primary dendrite and eutectics between them, as shown in Fig.4(c), but the shape of $\alpha$-Al dendrites is changed to small and uniform petal shaped dendrite from the previous coarse developed dendrite without modification. The volume fraction of $\alpha$-Al dendrite is decreased somewhat to about 55\%. Same as the unmodified alloy, the dendrites of modified alloy grows without directionality during solidification. Rare secondary arms or only a few bulges form on the primary dendrites. The mean length of the dendrites is about $50 \mu \mathrm{m}$. From the high magnitude image, Fig.4(d), it can be seen that the first dendrites of the modified alloy are short and thick in comparison with that of unmodified alloy, and seem petal shaped due to rare secondary dendrites. But a number of oval $\alpha$-Al dendrites of about $10 \mu \mathrm{m}$ are dispersed among the petal shaped primary dendrites. The volume fraction of eutectics between dendrite is slightly larger and the distribution of eutectics is more uniform than that of unmodified alloy.
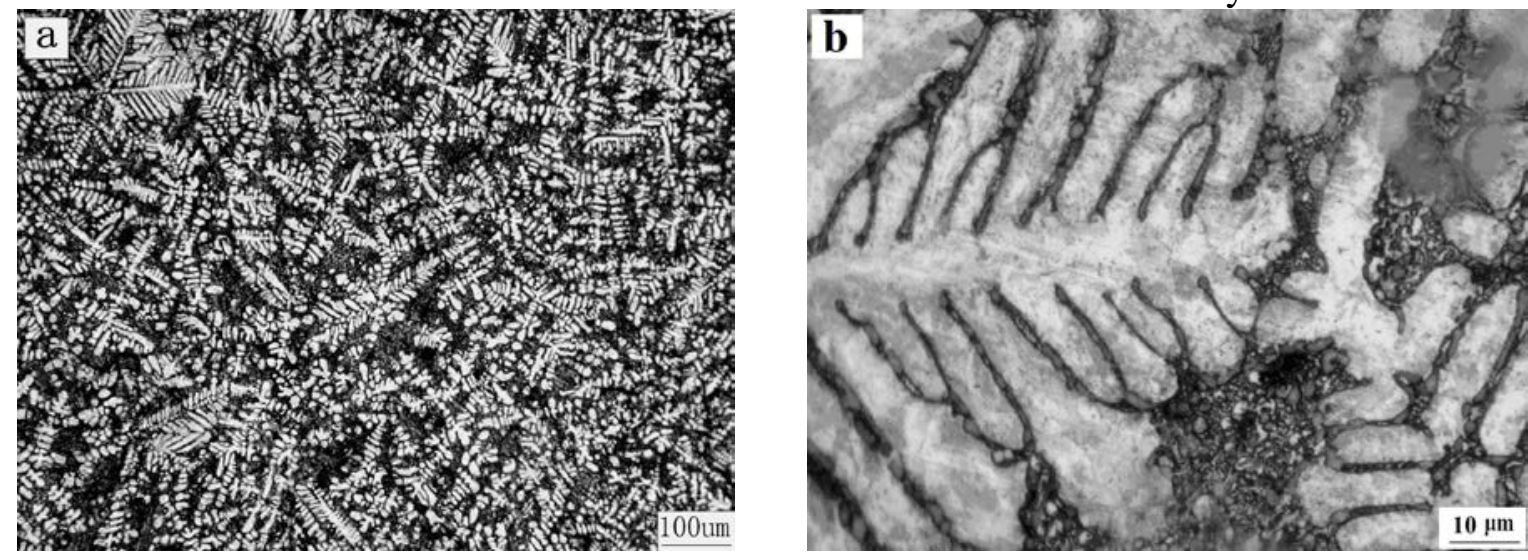

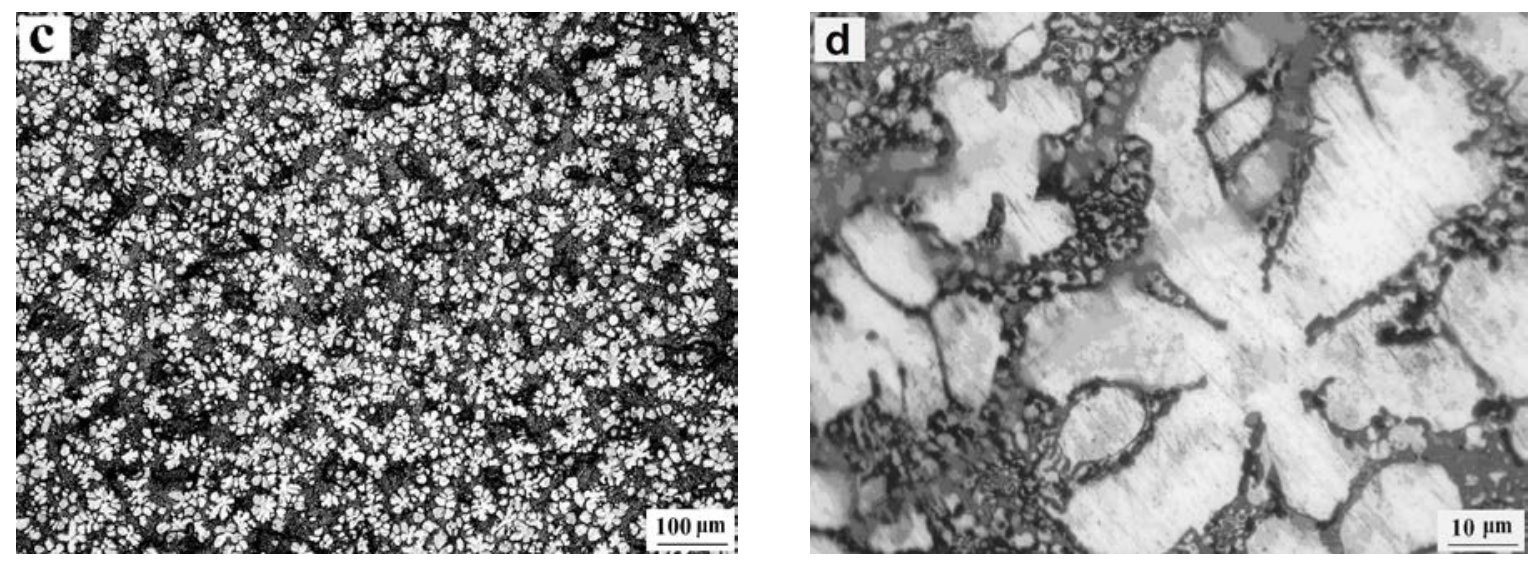

Fig.4. As-cast microstructures of ZA27 alloy, a, b un-modified; c, d modified

Solution heat treatment: Fig.5 shows the microstructures of investigated ZA27 alloy with and without modification after solution heat treatment at $370^{\circ} \mathrm{C}$ for 10 hours and quenched in water immediately. It is clear that the outlines of original coarse dendrites still appear in the unmodified alloy, and the volume fraction of $\alpha$-Al phase increased greatly to about $80 \%$, as shown in Fig.5(a). The details are shown in the high magnitude image, Fig.5(b). It can be found that no full independent dendrite really exists, and the fine lamellar eutectics and $\varepsilon$ particles of as-cast alloy are completely decomposed. The $\beta$ phase in eutectic is dissolved into $\alpha$-Al matrix, and $\eta$ phase is aggregated to interrupted blocks with $\varepsilon$ phase dissolved. So that a typical two-phase microstructure of $\alpha$ and $\eta$ is shaped by solution heat treatment on as-cast unmodified ZA27 alloy. With respect to the microstructure of modified ZA27 alloy, the outlines of original as-cast petal disappear after solution heat treatment due to the interconnect of primary dendrites resulted from the dissolution of intergranular structures, as shown in Fig.5(c). The volume fraction of $\alpha$-Al phase increases enormously to above 80 percent. From the high magnitude image, Fig.5(d), it can be seen that a typical $\alpha$ and $\eta$ two-phase structure forms by solution heat treatment due to the full decomposition of eutectics and dissolution of $\varepsilon$ phase, just like that of unmodified alloy. But the $\eta$ phase is more dispersive and uniform than that of unmodified alloy.
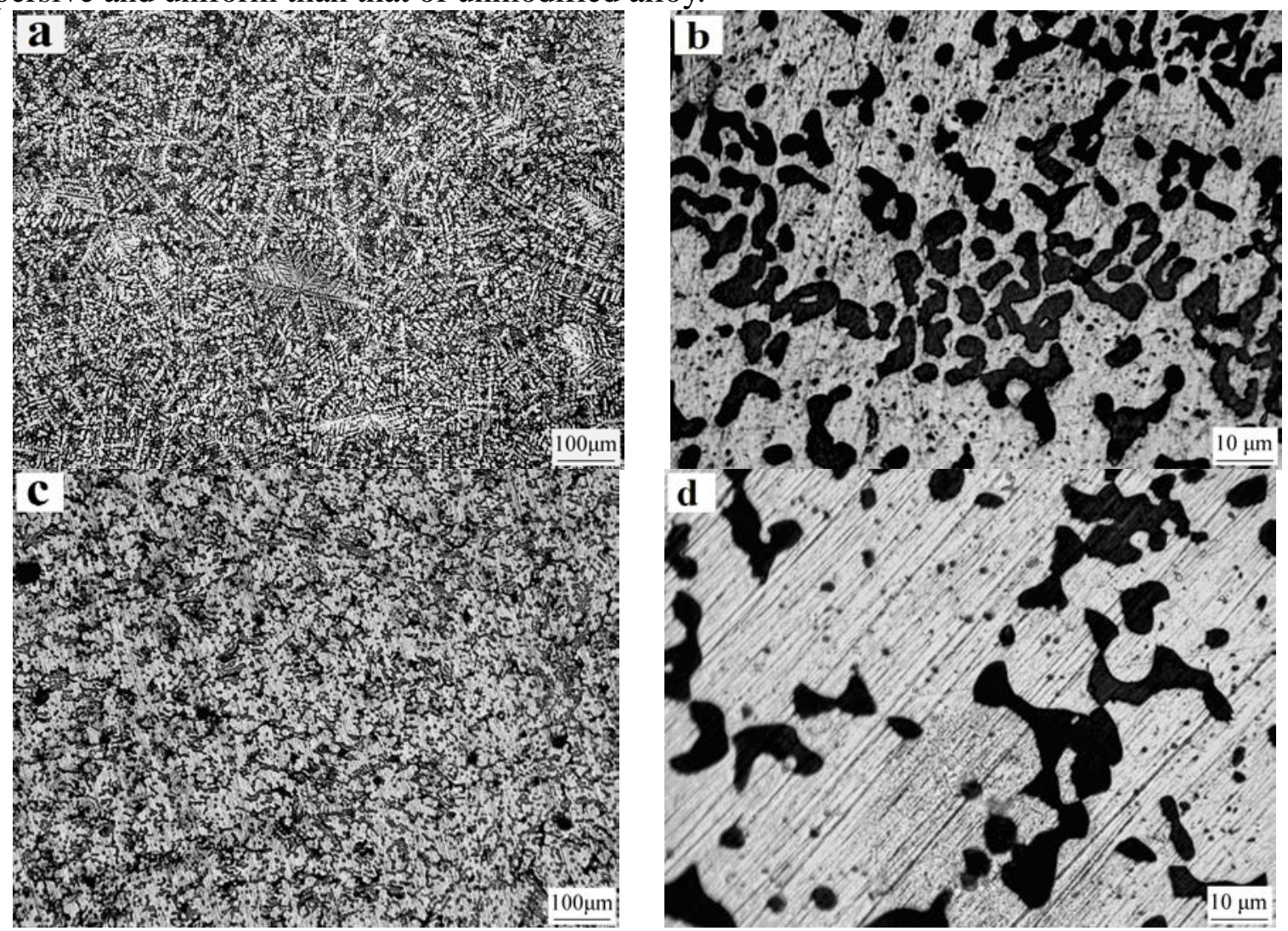

Fig.5. As-dissolved microstructure of ZA27 alloys, a, b-unmodified; c, d-modified 
Anneal heat treatment: Fig.6 shows the microstructures of investigated ZA27 alloys with and without modification after annealing at $320^{\circ} \mathrm{C}$ and holding for 3 hours and 18 hours respectively. For holding 3 hours, both alloys with and without modification remain the same shape of their as-cast primary $\alpha$-Al dendrites, in spite of the increase of the volume fraction of $\alpha$-Al phase, as shown in the low magnitude images of Fig.6(a) and Fig.6(e), respectively. From the high magnitude images, Fig.6(b) and Fig.6(f), it can be seen that annealing for 3 hours causes the structure between dendrites of both alloys coarse and lamellar apparently, and facilitates the precipitation of fine punctiform $\eta$ phase within the $\alpha$-Al dendrite. Prolonging the annealing time to 18 hours, the outlines of $\alpha$-Al dendrites of both alloys with and without modification are still distinguishable though they change to somewhat fuzzy due to the increase of volume fraction and the interconnection of $\alpha-\mathrm{Al}$ dendrites, as shown in Fig.6(c) and Fig.6(g). From the high magnitude images, Fig.6(d) and Fig.6(h), it can be seen that the eutectics between dendrites are decomposed thoroughly and aggregated to block $\eta$ phase. The precipitates of $\eta$ phase within $\alpha$-Al dendrite aggregate to scatter and grow obviously. Reversely, it is found that a few $\alpha-\mathrm{Al}$ precipitates appear within $\eta$ phase blocks. Furthermore, monotectoid reaction happens in anneal treatment of both alloys, which is the gray thin lamella structure in the high magnitude image, Fig.6(b, d, f and h), this is not found in the condition of solution heat treatment. It can be seen that the incorporated $\mathrm{Ti}$ and $\mathrm{Zr}$ modification restrains monotectoid reaction in the condition of short time anneal, that is annealing for 3 hours at $320^{\circ} \mathrm{C}$, by comparing Fig.6(b) with Fig.6(f), and promotes it in the condition of long time anneal, that is annealing for 18 hours at $320^{\circ} \mathrm{C}$, by comparing Fig.6(d) with Fig.6(g).

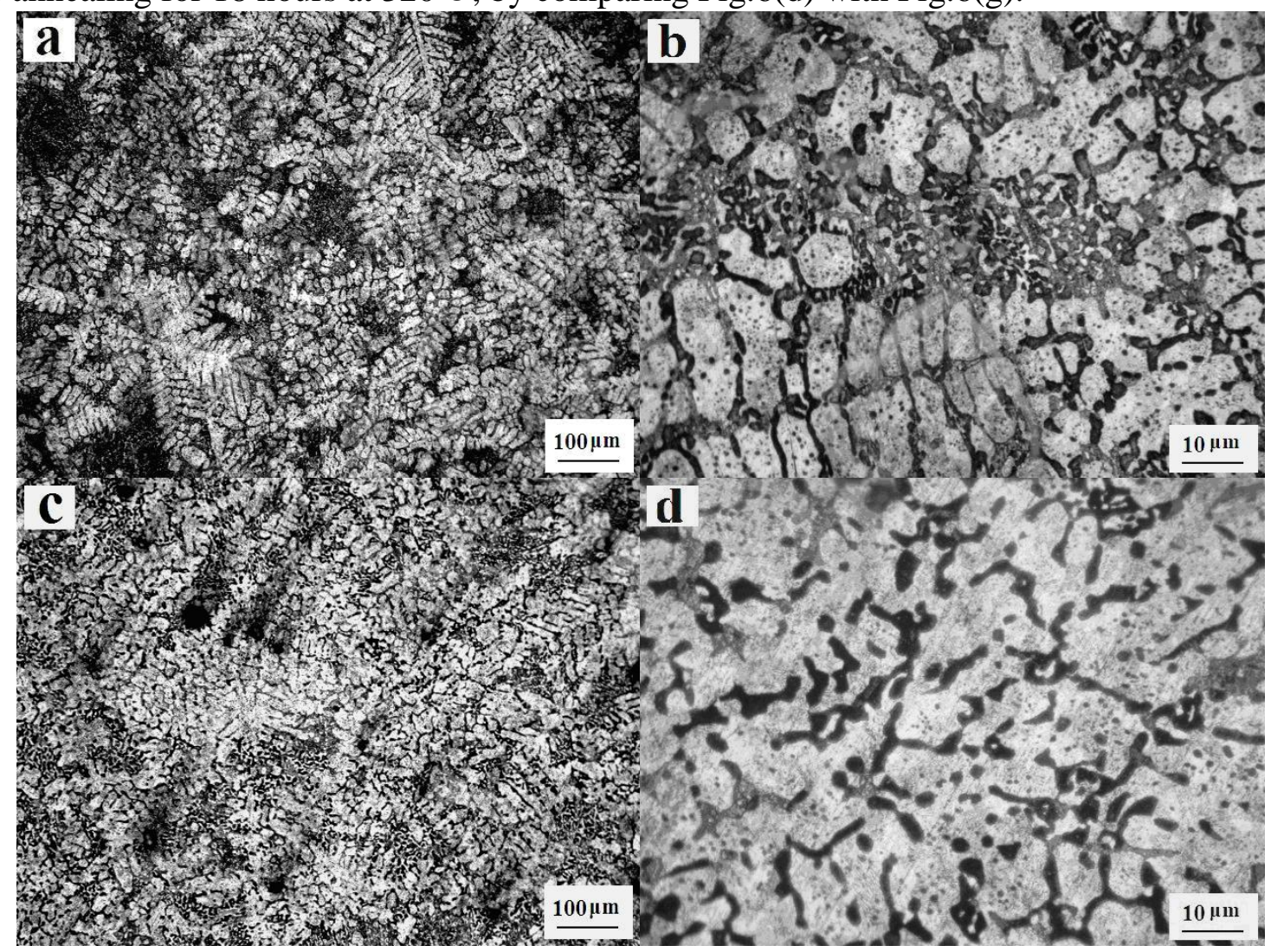




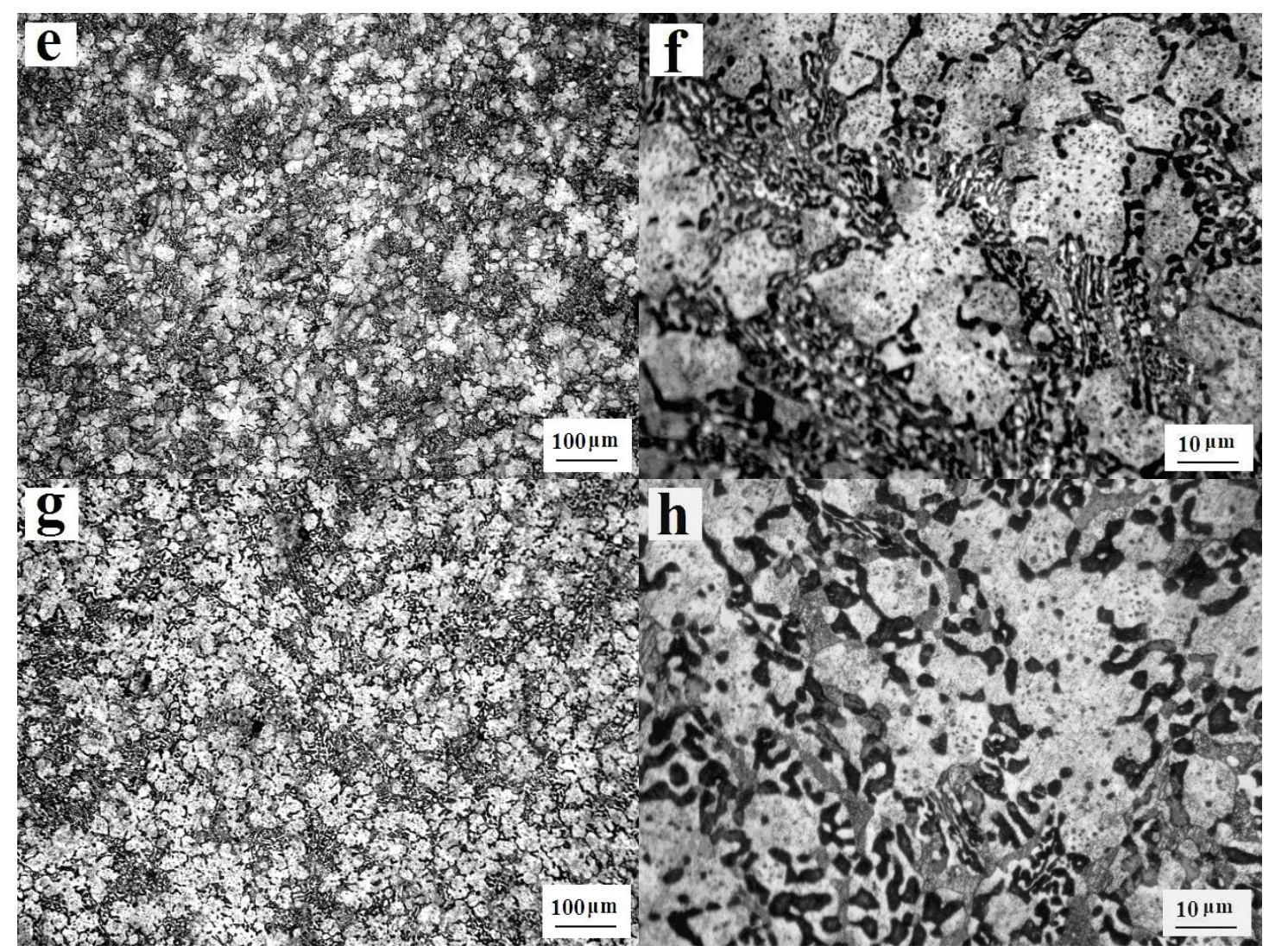

Fig.6. As-annealed microstructure of ZA27 alloys at $320^{\circ} \mathrm{C}$, a, b: un-modified, 3h; c, d: unmodified, 18h; e, f: modified, 3h; g, h: modified, 18h

\section{Results and Discussion}

As-cast microstructures: According to Al-Zn binary phase diagram, Fig.1, the solubility of $\mathrm{Zn}$ in $\mathrm{Al}$ is enormous at high temperature, with maximum solid solubility of $85 \mathrm{wt} . \%$ at eutectic temperature $\left(381^{\circ} \mathrm{C}\right)$. During equilibrium solidification process of ZA27 alloy, primary $\alpha$-Al solid solution is firstly precipitated, then eutectic reaction, $\mathrm{L} \rightarrow \alpha-\mathrm{Al}+\eta-\mathrm{Zn}$, happens at $381^{\circ} \mathrm{C}$. With reduction of temperature, the solubility of $\mathrm{Zn}$ in $\mathrm{Al}$ falls clearly and monotectoid reaction, $\alpha-\mathrm{Al} \rightarrow \alpha^{\prime}-\mathrm{Al}+\eta-\mathrm{Zn}$, happens at $277^{\circ} \mathrm{C}$. Within the subsequent cooling process, solubility of $\mathrm{Zn}$ in $\alpha^{\prime}$-Al decreases sharply to about $0.4 \%$ at room temperature. Similarly, solubility of Al in $\eta$ - Zn also decreases to about zero at room temperature. When a small quantity of $\mathrm{Cu}$ exists in solidification process of ZA27 alloy, a part of $\mathrm{Cu}$ atoms dissolve in primary $\alpha-\mathrm{Al}$ and the others are ejected to the melt of eutectics forming $\varepsilon-\mathrm{CuZn}_{5}$ compound in the later period of solidification process. The $\varepsilon$ phase is also regarded as $\mathrm{CuZn}_{4}$ [10] or $\mathrm{CuZn}_{3}$ [11], and distributes in grain boundaries in the form of $\varepsilon+\alpha$ binary eutectic or $\alpha+\eta+\varepsilon$ ternary eutectic. Tiny Mg in ZA27 alloy is commonly dissolved in $\alpha-\mathrm{Al}$ and $\eta-\mathrm{Zn}$. In the condition of nonequilibrium solidification, severe microsegregation occurs within $\alpha$-Al solid solution and results in more eutectics in ZA27 alloy. The solute segregation will make the primary $\alpha$-Al solid solution grow up to dendrite due to the enhanced constitutional supercooling effect, as shown in Fig.4(a, b). Eutectic reaction happens in the remainder melt between dendrites to form $\alpha+\eta$ and $\alpha+\eta+\varepsilon$ eutectic structures. The $\alpha$-Al phase of the eutectics at narrow secondary arms is easy to adhere the primary $\alpha$-Al dendrites forming divorced eutectic structure. The eutectics between dendrites are fine due to large degree of supercooling and high actual cooling rate, as shown in Fig.4 (b).

The solidification process and microstructure of ZA27 alloy will be remarkably affected by modification of tiny $\mathrm{Ti}$ and $\mathrm{Zr}$ addition. There are a few of modifying mechanism of $\mathrm{Ti}$ and $\mathrm{Zr}$ on ZA27 alloy. One point of view considers as that some intermetallic particles with high melting point, such as $\mathrm{TiA}_{3}, \mathrm{~A} 15 \mathrm{Ti} Z \mathrm{Zn}$ and $\mathrm{ZrA} 1_{3}$ [12-14], will form first in the solidification process of the modified alloy due to much higher melting points of $\mathrm{Ti}$ and $\mathrm{Zr}$ than that of $\mathrm{Al}$ and $\mathrm{Zn}$. These 
intermetallic particles can act as heterogeneous nuclei of primary $\alpha$-Al dendrite crystallization because of the favorable lattice matching of those particles with $\alpha$-Al. Another point of view [15] suggests that peritectic reaction of $\mathrm{TiA}_{3}$ and $\mathrm{ZrA} 1_{3}$ with melt, that is $\mathrm{L}+\mathrm{A} 1_{3} \mathrm{Ti} \rightarrow \alpha-\mathrm{Al}$, is the reason of Ti improving the nucleation of $\alpha-\mathrm{Al}$ dendrite and meanwhile refining eutectic structure of ZA27 alloy in solidification process. Nonetheless, no $\mathrm{TiAl}_{3}$ and $\mathrm{ZrAl}_{3}$ has been found by XRD detection in this investigation. Moreover, $\mathrm{Ti}$ and $\mathrm{Zr}$ incorporated modification has not refined eutectic structure in spite of coarsening and homogenizing effect, though it really refined primary $\alpha$-Al dendrite. So that it is thought that both heterogeneous nucleation and peritectic reaction are not suitable to explain the refining mechanism of primary $\alpha$-Al dendrite by modification in the present investigation, due to no heterogeneous nucleation particles are detected and no isometric crystal nucleation of $\alpha-\mathrm{Al}$ is observed. The probable modification mechanism may be that the segregation of $\mathrm{Ti}$ and $\mathrm{Zr}$ changes solutes distribution and the degree of constitutional supercooling of melt in front of primary $\alpha$-Al dendrite, which impede the growth of dendrite and restrain the formation of secondary dendrite or cause it remelt and fall off, so that bring about the change of final growing morphology and the refinement of primary $\alpha$-Al dendrite. The broken egg-like $\alpha$-Al blocks near the margin of petaloid dendrite, as shown in Fig.4, can be considered as formed like this. Whereas the exact modifying mechanism of Ti and $\mathrm{Zr}$ on primary $\alpha$-Al dendrite of ZA27 alloy and the effect on eutectic structure and the distribution of $\varepsilon$ phase are still waiting for further investigation.

Microstructures after heat treatment: The purpose of heat treatment for ZA27 alloy is to eliminate dendritic segregation and abnormal structure [16]. In the present investigation, solid solution heat treatment at $370{ }^{\circ} \mathrm{C}$ for 10 hours and quenching in water subsequently offered the alloy of apparent two phase microstructure, leaded to the interconnection of individual original dendrites and the elimination of eutectic structure and $\varepsilon$ compound among dendrites. This is due to the sufficient atomic diffusion of alloy at high temperature for long time, which makes dendritic segregation homogenize, the strip $\alpha-\mathrm{Al}$ in eutectic and $\varepsilon$ phase decompose into $\alpha$-Al phase, and the strip $\eta$ phase in eutectic grows through aggregating each other. This two phase microstructure is unstable and in favor of enhancing plasticity and toughness of the alloy. It can be seen in Fig.5 that after solid solution heat treatment the blocks of $\eta$ phase mainly distribute at the original grain boundaries of as-cast primary $\alpha$-Al dendrite, which means that the as-cast microstructure has significant influence on as-solid solution heat treated microstructure in ZA27 alloy. Modification by the addition of tiny $\mathrm{Ti}$ and $\mathrm{Zr}$ elements facilitates the solid solution heat treatment process of ZA27 alloy due to the fact that much uniform as-solid solution heat treated microstructure of modified alloy is obtained in comparison to unmodified alloy.

The heat treatment of annealing at $320^{\circ} \mathrm{C}$ for different times showed that in the case of short time heat preservation the volume fraction of $\alpha$-Al in ZA27 alloy increased not obviously, which indicated that eutectics and compounds at grain boundaries were not dissolved sufficiently. But the elimination of dendritic segregation and the coarsening of eutectics meant that short range atomic diffusion was still conducted in such situation. Moreover, a great number of dispersive precipitates of $\eta$ phase appeared in $\alpha$-Al dendrites during the subsequently cooling process. It can be seen from Fig. 6 that the eutectics in modified ZA27 alloy after 3 hour annealing were finer apparently than that of unmodified alloy. This is just right reverse to the as-cast condition and indicates that the modifiers $\mathrm{Ti}$ and $\mathrm{Zr}$ block atomic diffusion in annealing process. In the present investigation, the eutectic reaction temperatures of ZA27 alloy with and without modification were $393.9^{\circ} \mathrm{C}$ and $395.0^{\circ} \mathrm{C}$, the monotectoid reaction temperatures were $288.8^{\circ} \mathrm{C}$ and $292.5^{\circ} \mathrm{C}$, respectively. This meant that modification by trace $\mathrm{Ti}$ and $\mathrm{Zr}$ increased the eutectic and monotectoid temperatures of ZA27 alloy, as shown in Fig.3. So that, in the case of annealing for 3 hours at $320^{\circ} \mathrm{C}$, the eutectics were refined by modification of trace addition of $\mathrm{Ti}$ and $\mathrm{Zr}$, which is beneficial to improve the mechanical properties of ZA27 alloy. Prolonging the holding time of annealing to 18 hours, the volume fraction of $\alpha-\mathrm{Al}$ in ZA27 alloy obviously increased. This shows that the eutectics and compounds in the alloys were fully dissolved and two phase microstructure like solid solution heat treated microstructure was obtained after long time atomic diffusion during annealing. But there are a lot of dispersive precipitates of $\eta$ phase in $\alpha$-Al solid solution due to the slow cooling rate in 
comparison to quenching. Seeing the details of microstructure in Fig.6 (c,d) and Fig.6 (g,h), it can be found that the eutectics and compounds at grain boundaries in unmodified alloy were fully dissolved due to entirely atomic diffusion, and the outline of primary $\alpha$-Al dendrite was vague seriously due to the fact that $\alpha$-Al dendrites were integrated by the attachment of $\alpha$-Al phase in eutectic. The $\eta$ phase in eutectics was aggregated to block and distributed at the original grain boundaries after 18 hours annealing. However, the outlines of independent $\alpha$-Al dendrites were still clear considerably in the modified ZA27 alloy after 18 hours annealing. It indicates that the $\alpha-\mathrm{Al}$ phase in eutectic was not adhered completely to the primary $\alpha$-Al dendrite though the eutectics is coarsened seriously and the presence of thick lamellar of $\alpha-\mathrm{Al}$ and $\eta$ phase blocks. This indicates again that modification by trace $\mathrm{Ti}$ and $\mathrm{Zr}$ can hinder the atomic diffusion in ZA27 alloy during annealing process.

\section{Conclusions}

(1) Incorporated modification by the addition of trace Ti and $\mathrm{Zr}$ changed coarse primary $\alpha-\mathrm{Al}$ dendrite in as-cast ZA27 alloy to fine petaloid dendrite without secondary arms, though the phase constituent was not varied. The mechanism of modification is probably that the existence of tiny $\mathrm{Ti}$ and $\mathrm{Zr}$ atoms changed the solute distribution and the degree of constitutional supercooling, and obstructed the growth of $\alpha$-Al dendrites and the formation of secondary dendrites.

(2) Solid solution heat treatment for 10 hours at $370^{\circ} \mathrm{C}$ fully eliminated the existence of eutectics and compounds of ZA27 alloy with and without modification. Modification by trace $\mathrm{Ti}$ and $\mathrm{Zr}$ improved the uniform distribution of $\eta$ phase after solid solution heat treatment.

(3) Annealing for 3 hours at $320^{\circ} \mathrm{C}$ not changed the morphology of primary $\alpha$-Al dendrite in both modified and unmodified as-cast ZA27 alloys, but caused eutectics and $\varepsilon$ particles coarsen and fine $\eta$ phase particles precipitate within primary $\alpha$-Al dendrite. Modification can restrain the coarsening of eutectics effectively. Prolonging annealing time to 18 hours, two phase structure of block $\eta$ phase and $\alpha$-Al dendrites was obtained. Modification resulted to the refining of lamellar eutectic structure of $\alpha-\mathrm{Al}$ and $\eta$-Zn phases due to the obstruction of atomic diffusion by the addition of $\mathrm{Ti}$ and $\mathrm{Zr}$.

\section{Acknowledgement}

In this paper, the research was supported by the National Students'innovation and entrepreneurship training program (Project No. 201410635002).

\section{References}

[1] Anders Nilsson, Per Gabrielson, Jan-Eric Ståhl. Zinc-alloys as tool materials in short-run sheet-metal forming processes: Experimental analysis of three different zinc-alloys [J]. Journal of Materials Processing Technology, 2002 (125-126) 806-813.

[2] Zhu Y.H., Torres V.G., Pina B.C. Complex microstructural changes in as-cast eutectoid Zn-Al alloy [J]. J. Mater. Sci., 1994 (29)1549-1552.

[3] Wei X.W., Shen B.L. Effect of rare earths on phase transformation in as-cast ZA27 alloy during compressive creep [J]. Rare Metals, 2003 (22) 259-264.

[4] Yang LIU, Hong-ying LI, Hao-fan JIANG, Xiao-chao LU. Effects of heat treatment on microstructure and mechanical properties of ZA27 alloy [J]. Transactions of Nonferrous Metals Society of China, 2013 (23) 642-649

[5] Hou P.J., Ni F., Long R. Study on the modifying mechanism of high aluminium Zinc alloy by titanium and zirconium [J]. Research Studies on Foundry Equipment, 2003 (1) 12-15. 
[6] Wang K.F., Bai Y.Q. Effect of heat treatment on microstructure and mechanical properties of ZA27 zinc alloy [J]. Materials of mechanical engineering, 1999 (1) 23-26.

[7] Y.H. Zhu, S. To, X.M. Liu, W.B. Lee. Microstructural changes inside the lamellar structures of alloy ZA27 [J]. Materials Characterization, 2006 (57) 326-332

[8] Tan Y.Y. Effect of composite modificators on microstructure and mechanical properties of ZA27 zinc alloy [J]. Journal of nanjing university of science and technology, 2002 (26) 547-551.

[9] Massalski T.B., Murray J.L., Bennett L.H., et al., 1988. binary alloy phase diagrams. American society for metals.

[10] Savaskan T., Murphy S. Decomposition of Zn-A1 alloys on quench-aging [J]. Mater Sci Technol, 1990 (6) 695-703.

[11] Lu W., Yan B. Progress in casting Zn-Al alloy and application. Shanghai Nonferrous Metals [J], 200425 (1) 13-17.

[12] Liu J.S., Shu Z., Li C.P. Effect of Ti on microstructure and properties of Zn-A1alloy [J]. Acta Metallurgica Sinica, 1993 (29) 487-490.

[13] Lu S., Xu G.,J., Chen T.J. Effect of isothermal treatment on microstructure evolution of semisolid ZA27alloy [J]. Hot Working Technology, 2000 (1) 42-44.

[14] Tan Y.Y., Yan H.F. Effect of rare earth on phase components of ZA27 alloy [J]. Chinese journal of nonferrous metals, 2001 (11) 742-747.

[15] Biljana Bobic, Jelena Bajat, Zagorka Acimovic-Pavlovic, Marko Rakin, Ilija Bobic. The effect of T4 heat treatment on the microstructure and corrosion behaviour of Zn27Al1.5Cu0.02Mg alloy [J]. Corrosion Science, 2011 (53) 409-417.

[16] T.J. Chen, Y. Hao, J. Sun, Y.D. Li. Effects of Mg and RE additions on the semi-solid microstructure of a zinc alloy ZA27 [J]. Science and Technology of Advanced Materials, 2003 (4) 495-502. 